\title{
THE STATUS OF THE WORLD'S PUBLIC-DOMAIN DIGITAL TOPOGRAPHY OF THE LAND AND ICE.
}

\author{
Michael Wolf and Duncan Wingham.
}

Mullard Space Science Laboratory, University College London.

\begin{abstract}
There has been no reasonably comprehensive survey of what digital, elevation models of the Earth's land surface exist in the public-domain. We have performed a survey of these data, and we report on the coverage and cost of the data we have established. To qualify for inclusion in our coverage, we required the data to be available to the general public, obtainable from a specific, identified institution, and to have a determined cost. We have established that at $100 \mathrm{~m}$ resolution coverage exists of most of the the developed world. In the United States and Australia, the data are available at cost, at around $3000 \mathrm{~km}^{2} \mathrm{f}^{-1}$. In the remaining countries, the data are available from mapping agencies with varying commercial pricing strategies. The total cost of the data we have identified is $£ 1,688,312$. For much of the world we are unable to confirm the existence of such data, and our experience is that in these regions it will prove difficult to obtain digital, elevation data, if, indeed, it exists at all.
\end{abstract}

\section{Introduction.}

A global, digital topographic data-set for workers in geophysics, geology, glaciology, hydrology and ecology, has become a pressing need. The next decade will see large space programmes in the United States and Europe whose task is to monitor the Earth's atmosphere, oceans, ice and land surfaces. The full and timely exploitation of the land and ice data requires a digital description of the topography of these surfaces. The widespread availability of powerful computers has also led to growing interest in the modelling of geophysical, geomorphological, hydrological and ecological studies that require the Earth's topography to provide parameters on continental and regional scales [Rodrigue and Thompson, 1987; Anderson, 1988; Burke and Dixon, 1988; Mueller and Zerbini, 1989; Hutchinson and Dowling, 1991; Moore et al, 1991]. It seemed to us, therefore, that it would be useful to the geophysical and Earth science community at large to provide an inventory of what digital topographic data exists in the public domain. In writing this letter, our purpose is to summarise the coverage and cost of the Earth's land surface elevation models, as far as we have been able to establish it since we believe this information will be useful to those planning future programmes that measure the Earth's topography, or that require it as ancilliary observations, as well as those seeking digital, elevation models for particular parts of the world.

While the world's coverage of paper maps has been surveyed a number of times by the United Nations [United Nations, 1976, 1983, and 1990; Brandenberger and Ghosh, 1985] and by Parry and Perkins [1987, 1989], surveys of digital, elevation models, are generalised or geographically

Copyright 1992 by the American Geophysical Union.

Paper number $92 \mathrm{GL} 01886$

0094-8534/92/92GL-01886\$03.00 limited. Kubik [1988] remarks in general terms on databases in Europe and the United States; Allder and Caruso [1982] describe the United States Geological Survey (USGS) collection; Rodrigue and Thompson [1987] discuss the United States; Moore et al. [1991] describe sources of models of the United States and Australia.

A catalogue of digital elevation data produced in the United States and Canada is held in the National Aeronautics and Space Administration (NASA) Master Directory (NMD). The United States Geological Survey (USGS) Earth Resources Observation System (EROS) data centre catalogues United States, Canada and Australian models. We are also aware of other organisations creating topographic databases, but which, at present, have very few entries in their catalogue.

We have restricted our survey to gridded, elevation data. Some agencies supply digital, contour data, of which the best known is the Digital Chart of the World, which is shortly to be released by the U.S. DMA and other agencies. We have also learnt of a number of extensive datasets of parts of the world's topography that are not public-domain. Of these, the best known is the DMA's digital terrain elevation data (DTED). However, these data are out of reach to the general community, and we have not included it in the coverage described here.

\section{The survey of the world's digital, elevation data.}

The survey of the world's digital elevation data was conducted in the period October 1991 to April 1992. The method of our search was to determine and contact potential producers to request information on digital, elevation data they held, available to the public. The principal source of potential producers was catalogues of over 200 of the world's map producers [Parry and Perkins, 1987; Parry and Perkins, 1989; Hodgkiss and Tatham, 1986]. Searches of the academic literature from 1984 led to the identification of over 100 possible sources. A complete list of the organisations and individuals we contacted is given by Wolf and Wingham [1992].

In all, 352 separate enquries were made by letter. Of these, 80 replies were received. 31 of these gave details of existing digital, topographic data. In cases where no reply was recieved, follow-up communications were made when we had reason to believe that data was existent. The response was good for enquiries in the United States, Western Europe and Australia. Otherwise, the response was poor. In Africa, the official mapping agencies of Keyna, Nigeria, Zimbabwe and South Africa replied. In Asia, the agencies of Bangladesh, Thailand, the Philippines and Nepal replied. In Eastern Europe, South and Central America we obtained no replies from official agencies.

3. The coverage and cost of the world's digital, elevation models.

The best global, digital, elevation map of the world's solid surface is ETOP05 [Laughridge, 1986], distributed by the 
United States National Oceanographic and Atmospheric Administration (NOAA). This well known model is compiled from a mixture of 5 arc-minute and 10 arc-minute continental datasets, and interpolated to a grid of 5 arc-minute, or 9.25 $\mathrm{km}$ at the equator. It has been regridded and had additional bathymetry added by the Technical University of Gratz [Wieser, 1987], to form TUG-87, but this is substantially the same over the land surfaces.

At higher resolutions, global coverage does not exist. The coverage of the world that we have established at $100 \mathrm{~m}$ resolution is shown in Figure 1. We have taken care to establish that coverage shown in this figure is available to the public through an identified source; the existence of an elevation model is not sufficient to be included in the figure. At $500 \mathrm{~m}$ resolution, the picture is similar, with additional data for South Africa, Japan, and 30\% of Australia.

The state mapping agencies of the Republic of Ireland, Bangladesh, Zimbabwe, the Phillipines and Nepal have confirmed that no data exists in the public domain. The military mapping agencies of Portugal and Turkey have confirmed that digital, elevation data is not available to the public. Italy is known to produce $250 \mathrm{~m}$ resolution digital, elevation models, but we have been unable at the time of writing to identify the cost of these data. The Surveys and Land Information of South Africa are planning to distribute a $400 \mathrm{~m}$ gridded data set derived from 1:150,000 aerial photography. We have not been able to establish the existence of public-domain, gridded, elevation data of much of the world, including South and much of Central America, China,
India, and most African and Arab nations. Most of the Northern hemisphere, and substantial parts of the Southem hemisphere, is modelled at 3 arc second resolution by the classified, DTED level-one data. The DTED program is ongoing, and the DMA will continue to expand its digital database over unmapped regions [S. Jenson personal communication 1992]

Table 1 gives details of the datasets identified. The total cost of all the data in Table 1 is $£ 1,688,312(\$ 3,238,183)$. The cost of all data with resolutions equal to, or higher than $100 \mathrm{~m}$ is $£ 1,638,420(\$ 3,142,490)$. This figure includes multiple datasets of a region, where available; by chosing only the least costly data over any region, this figure can be reduced to $£ 868,989$ ( $\$ 1,666,721)$ The suppliers of the United States data, the USGS, and the Australian data, the National University of Australia, supply the data at cost of around $3000 \mathrm{~km}^{2} £^{-1}$. The remaining institutions sell these data commercially, typically at costs of $0.2 £ \mathrm{~km}^{-2}$, i.e. an increase of a factor 600 or so.

\section{Discussion.}

The coverage we have established shows that high resolution, elevation data largely exists in the first world. For much of the world, however, there appears to be no data of sufficient resolution for most scientific purposes save global studies. The principal deficiency in our survey is the large regions of the world for which we were unable to obtain confirmation that elevation models existed in the public

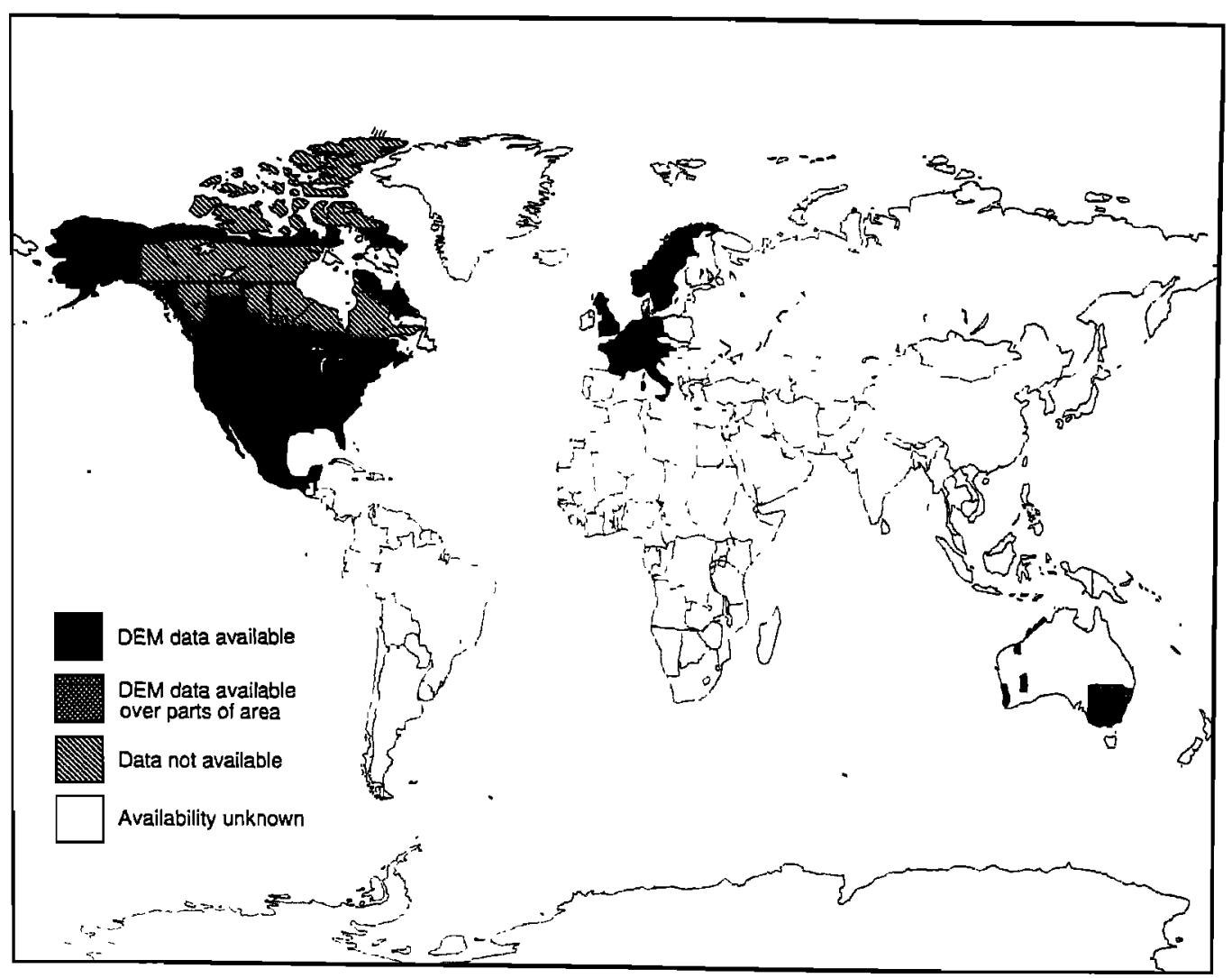

Fig. 1. A map showing the geographical coverage of the world's public-domain, gridded, digital, elevation models with a resolution equal to or better than $100 \mathrm{~m}$. The coverage shown in this figure includes only those models that are public-domain and have an identified distributor and cost. The absence of coverage indicates that there is apparently no public-domain coverage, not that coverage does not exist. The details of the models, their distributor and cost are given in Wolf and Wingham (1992). 


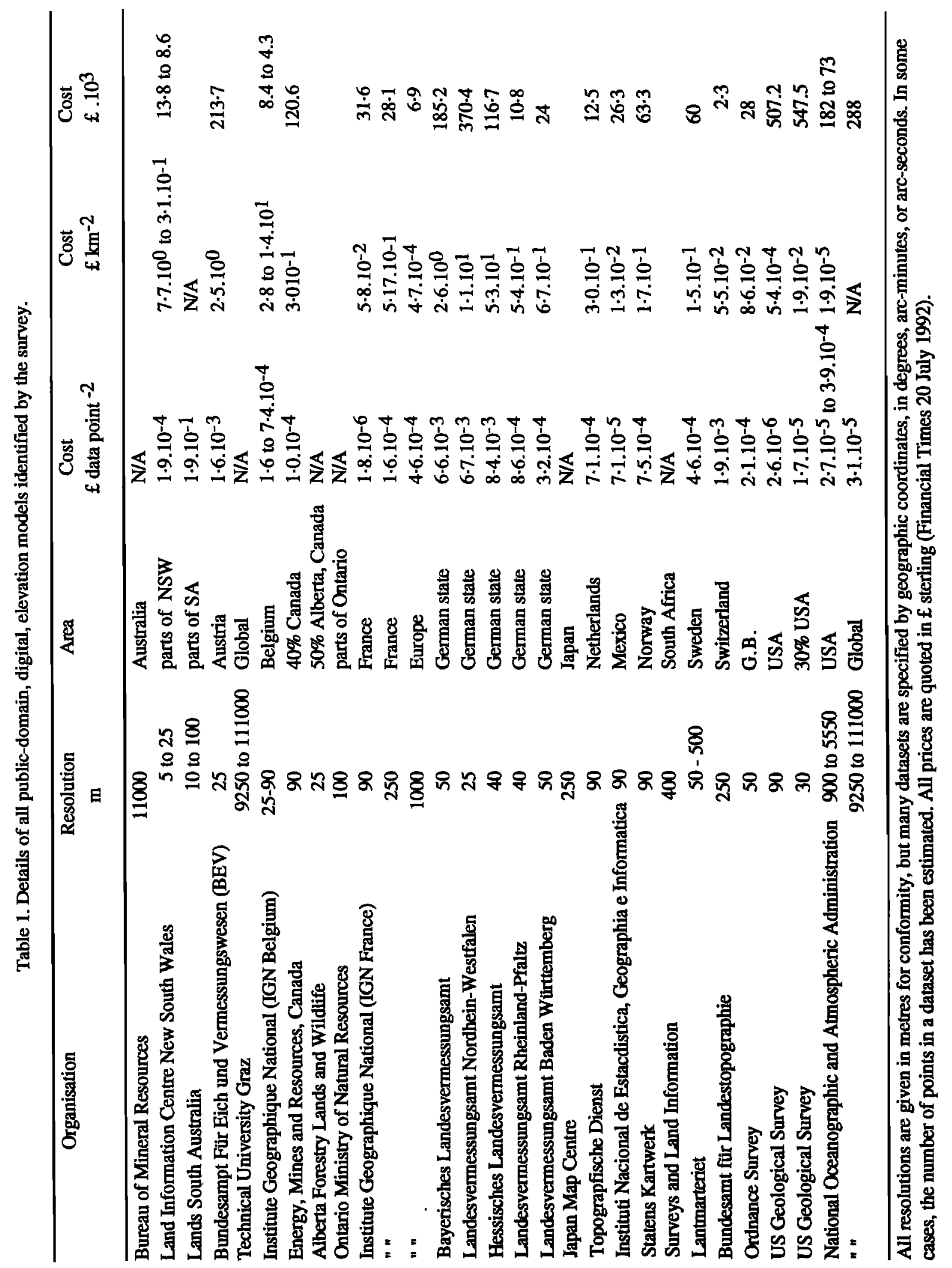


domain. In exercises of this sort, however, one is very largely dependent on the willingness of agencies to provide information. However, much of the data we did locate is sold commercially, and it is unlikely, in our view, that if such data were available, we would not have learnt of it, at least as potential customers. In some parts of the world, elevation data is regarded as of potential military value to an enemy, and both the data and its existence are classified. Our view is that workers requiring digital, elevation data in these regions of the world will find it difficult to obtain, if, indeed, it exists at all.

The pricing policies of national agencies are often determined by government policy [G. Maffini 1990]. To be useful to the scientific community, elevation models must be easy to obtain and inexpensive. This is particularly true if one wishes to use the data to model continental or regional processes. We emphasise that the cost of these data may make them as inaccessible to the scientific user as if they did not exist, and we would encourage national institutions to adopt a policy that allows for non-commercial use, such as exists in the United States.

There is no question that the most important, digital, elevation dataset that is not in the public-domain is the DTED, level one model, although its vertical accuracy is less than many scientific investigations require. The USGS and the DMA are activly pursuing processing and policy alternatives that may lead to the release of DTED, possibly in modified form, to the scientific community [S. Jenson personal communication]. The difficulties we have experienced in determining the existence of data, the cost of what data exists, and the sensitivity of some countries to the availability of these data, form a powerful argument that future improvements in our models of the Earth's topography should be obtained from space, by a single organisation that is prepared to distribute the data at cost.

We have compiled a catalogue [Wolf and Wingham, 1992] of the organisations we surveyed and the data-sets we have located. The catalogue allows workers to determine quickly if digital, elevation models are available for the area of their interest, of sufficient quality for their purposes, and it locates the producers and cost of the models. This catalogue is available from the authors at the address given in the reference.

Acknowlegements. Many individuals helped us in our task of locating elevation models, and it is impossible to thank all of them by name. However, Sue Jenson, of the EROS Data Centre, Gordon Petrie, of the University of Glasgow, and Joe Mousset and Ingo Wilsky, of CERCO, Reiner Rommel of the Technical University of Delft, Simon Ekholm of the Kort-og Matrikelstyrelsen, and Prof. C. Merry, of the University of Cape Town, were extremely helpful in the early stages of our search in directing our attention to particular suppliers and models. We would also like to thank the many people who passed on our request for information to other interested parties on our behalf. This work was supported by the United Kingdom Defence Research Agency, contract number 2047/144EXR3.

\section{References.}

Allder, W. R., Caruso, V. M., Pearsall, R. A., and Troupe, M. I., An Overview of digital elevation model production at the USGS, Proc. Aute Carto Eive.
ASPRS/American Congress on Surveving and Mapping Crystal City, Virginia, 23-32, 1982.

Anderson, M.G., Modelling geomorphological sustems, $458 \mathrm{pp}$, John Wiley \& Sons, New York, 1988.

Brandenberger, A. J., and Ghosh, S. K., The Worlds Topographic and Cadastral Mapping Operation, Photogrammetric Eng. and Remote Sensing, 51, 437-444, 1985.

Burke, K., and Dixon, T. H., (Eds.), NASA Topographic Science Working Group Report to the Land Processes Branch, Earth Sciences and Applications Division, 64 pp NASA Headquarters, Lunar Planitary Institute, Houston, Texas, 1988.

Hodgkiss, A. G., and Tatham, A.F., Keyguide to information sources in cartography, Mansell, London, 1986.

Hutchinson, M. F., and Dowling, T. I., A continental hydrological assessment of a new grid based digital elevation model of Australia, Hydrological Processes. 5, 1, 45-58, 1991.

Kubik, K., Digital Elevation Models, Review and Outlook, International Archives of Photogrammetry and Remote Sensing, Kyoto, Japan, Vol. 27(B3), Commission III, 415-425, 1988.

Laughridge, M. S., Relief Map of the Earth's Surface, EOS Trans., 67, 121, 1986.

Maffini, G., The role of public domain databases in the growth and development of GIS, Mapping_Awareness, 4, 2 , 49-54, 1990.

Moore, I. D., Grayson, R. B., and Ladson, A. R., Digital Terrain Modelling: a review of Hydrological, Geomorphological and Biological Applications, Hydrological Processes 5, 3-30, 1991.

Mueller, I.I, and Zerbini, S., (Eds.), The interdisciplinary role of space geodesy, Lecture Notes in the Earth Sciences, Springer-Verlag, Berlin, 1989.

Parry, R. B., and Perkins, C. R., World Mapping Today 583 pp. Butterworths, London, 1987.

Perkins, C. R., and Parry, R. B., (Eds.), Information Sources in Cartography, Bowker-Saur, London, 1990.

Rodrigue, M., and Thompson, L., The availability and use of digital topographic data, Proc. Auto Carto 6, 580-587, 1987.

United Nations, World Cartography XIV, XVII. XX. Report ST/ESA/SER.J/14, ST/ESA/SER.L/17, ST/TDC/14, Department of Technical Co-operation and Development United Nations, New York, 1976, 1983, 1990.

Wieser, M., The Global Digital Terrain Model TUG87, Internal Report of the Institute of Mathematical Geodesy, 4pp., Technical University of Graz, Graz, Austria, 1987.

Wolf, M., and Wingham, D.J., A suryey of the world's digital elevation data. Global Topography Team Report 4010/04-92/002, 87 pp., Mullard Space Science Laboratory, Holmbury St. Mary, Dorking RH5 6NT, 1992.

M. Wolf and D.J. Wingham, Mullard Space Science Laboratory, University College London, Holmbury St. Mary, Dorking, Surrey, RH5 6NT, U.K.

(Received June 16, 1992; acceptedAugust 4 1992.) 